\title{
Application of fitball aerobics means in the system of physical education of female students of non-sporting specialties
}

\author{
Symonik A. V. ${ }^{1 A B C D E}$, Chernenko O. Ye. ${ }^{1 A B D E}$, Chernenko A. Ye. ${ }^{2 A B C}$, Serdyuk D. G. ${ }^{1 B C D E}$, \\ Kokarev B. V. ${ }^{1 \mathrm{ABCE}}$, Bulakh S. M. ${ }^{1 \mathrm{ABCD}}$, Hurieieva A. M. ${ }^{3 \mathrm{ACDE}}$ \\ ${ }^{1}$ Department of Physical Culture and Sports, Zaporizhzhya National University, Ukraine \\ ${ }^{2}$ Department of Physical Culture, Olympic and Non-Olympic Sports, Zaporizhzhya National Technical University, \\ Ukraine \\ ${ }^{3}$ Department of Physical Rehabilitation, Sports Medicine, Physical Education and Health, Zaporizhzhya State \\ Medical University, Ukraine
}

Authors' Contribution: A - Study design; B - Data collection; C - Statistical analysis; D - Manuscript Preparation; E - Funds Collection.

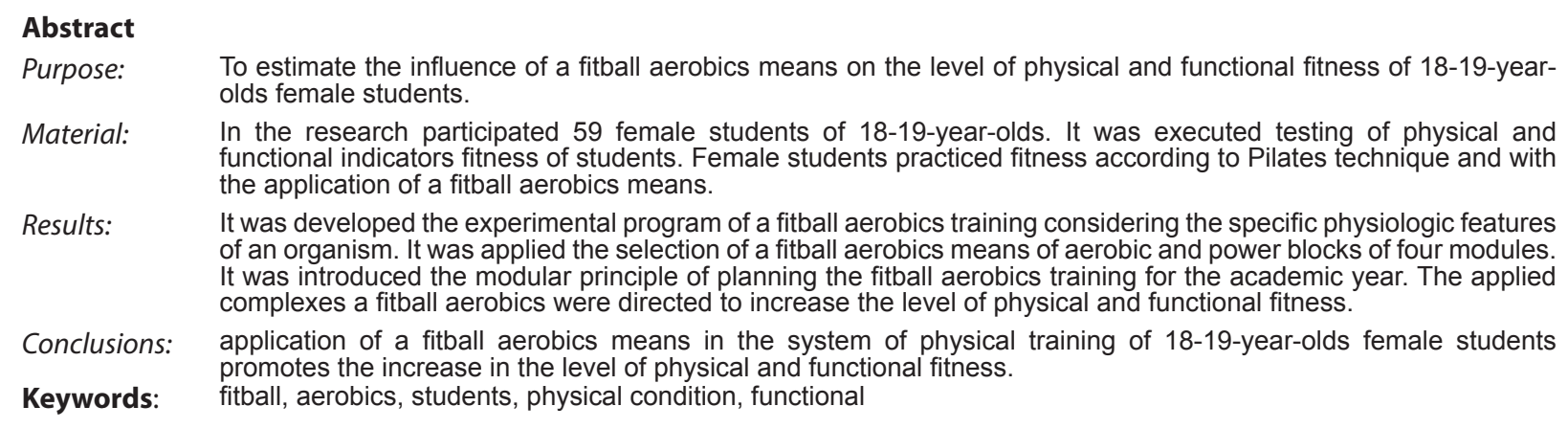

\section{Introduction}

Nowadays there is essential growth of popularity of different types of fitness in student's youth in years [1, 2]. The fitball aerobics attracts modern students with the availability, simplicity, a high emotional background expressed by all-improving direction $[3,4]$.

Many experts in the field of physical training presuppose that practical introduction of aerobics means in the system of physical training promote significant efficiency improvement of this process. Mastering various exercises of a new modern kind of a fitball aerobics allow to strengthen health and to improve physical fitness [5]. The wide arsenal of aerobics kinds allows to apply its means depending on target orientation [6]: cardio programs [7]; aerobics programs [8]; functional training $[9,10,11]$ and so on.

There are a lot of works of domestic and foreign researchers devoted to opportunities of application of a fitball aerobics means for improvement of some components of a physical condition of different categories of the population.

It is examined the introduction of a fitball aerobics means for: rehabilitation of women in the postnatal period [8]; developments of the computer program for differentiation of physical loads among women of the first mature age [9]; rehabilitation actions for decrease of back pain [12]; prevention of backbone diseases in female students [13]; improvement of body posture and decrease in risk of back pain in persons who lead an inactive lifestyle $[14,15]$; implementation of therapeutic

\footnotetext{
(C) Symonik A.V. , Chernenko O.Ye., Chernenko A.Ye., Serdyuk D.G., Kokarev B. V., Bulakh S. M., Hurieieva A. M., 2018 doi:10.15561/20755279.2018.0308
}

or rehabilitation programs [16].

Biological features of women's organism determine the need for essential reorganization of improving training process [17]. It is necessary to consider phases of a menstrual cycle in planning training loads [18]. That is the implementation of the individual approach to women's training process [19]. On the other hand, there is a need for new methods which allow to improve a functional condition of women organism and promote the increase in results of training $[20,21]$. Researchers proved the efficiency of development of separate physical qualities by fitball aerobics means [22]. It is studied features of physical training planning of females and women consider their morphofunctional and separate physiologic features $[19,23]$.

The application of aerobics means promotes: increase in motivation level to training in students [24]; optimization of separate components of physical development [9]; development of aerobic endurance [8]; to the substantial increase in the level of physical fitness [25]; improvement of nervous-muscular conductivity [26]. At the same time, the number of researches in this direction is insufficient. Most of them are limited by the application of fitball aerobics means for rehabilitation (recovery) of mature age persons after the postponed injuries or diseases [27]. Other directions of researches concerning youth participation had an insufficient methodical background and were limited by studying only of separate indicators of a physical condition of an organism.

Thus it wasn't conducted the complete, complex research of effective application of a fitball aerobics means in the system of physical training in students of higher educational institutions. 
Hypothesis. It is presupposed that introduction of a fitball aerobics means in the system of physical training among female students of 18-19-year-olds promotes optimization of physical and functional fitness.

The purpose of the research is to estimate the influence of a fitball aerobics means on the level of physical and functional fitness of 18-19-year-olds female students.

\section{Material and methods.}

Participants. In the research participated 59 female students of 18-19-year-olds of non-sporting specialty. Selection in experimental (EG, $n=29)$ and control groups $(\mathrm{CG}, \mathrm{n}=30)$ was provided with the method of a casual sample.

Design of a research. Testing of physical and functional fitness indicators was executed at the beginning (the first stage of an experiment) and in the end (the second stage of an experiment) of the academic year.

Results of the first stage of the experiment were applied for the development of the experimental program of fitball aerobics training. Students of CG and EG had additional extra training (2 times for a week). Female students practiced fitness according to Pilates technique [28] and with the application of a fitball aerobics means respectively.

It was offered to determine for students of experimental group 132 hours for a fitball aerobics training in the 3rd and 4 th semesters of the academic year. It is 64 hours ( 32 training) during each semester. The training was carried out 2 times a week (60-70 $\mathrm{min})$. In the course of each training, the female students carried out dancing and power exercises. The activity of female students at fitball aerobics training was organized by frontal method (all students executed exercises simultaneously).

Physical loads were differentiated by the teacher. Depending on the level of physical fitness, the female students were divided into groups and were ranked: in the first group - female students with low and below the average fitness level, in the second group - with average and above the average level.

The exercises were selected for the purpose of influence: on the functional systems of an organism, figure correction, reduce fatigue and nervous tension; emotional influence on the organism. The program contained 4 modules in which loads were distributed according to the didactic principles of physical training process creation. Loads on training increased gradually, considering the level of a physical condition.

In the aerobic block were applied basic steps of improving aerobics and their combination with the different motions of fitball (up and down hands, push-ups in deferent directions holding a fitball; beat off a fitball from a floor; play the fitball etc). Such selection of the aerobic block means promoted the increase in aerobic opportunities of an organism and improvement of a functional condition of the cardiorespiratory system. In the peak of aerobic loads heart rate was 150-160 bpm.

In the first module (the aerobic block) was train technique of basic steps execution of improving aerobics with the simple motions with a fitball. Steps were executed at slow speed (one step in 2-time signature) 4 repetitions. After that were executed 8-16 repetitions of each step in every time signature. It was applied the intermediate march for preparation to execution of the following step.

At the one training were executed 4-8 steps depending on coordination complexity of these steps. After two months of training, steps were executed 4-8 repetitions of each step consistently without intermediate march. It was executed different kinds of basic steps (a march forward back and forth, sidestep back and forth, right-left, open step back and forth, right-left etc.).

In the power block of the first module exercise executed as one series of 10-16 repetitions (slow speed). Special attention was paid to the method of exercises' execution and the regular breathing (during exercise execution- deep inhale, during rest - a deep exhale).

The breath holding is prohibited. Heart rate during power exercises execution is $120-130 \mathrm{bpm}$. Loads for females with different level of a physical condition is regulated by motion amplitude and preparatory position.

In the second module was observed a gradual increase in aerobic and power load. In the aerobic block were applied motions of medium-shock load (Hi-lo). They are characterized by the existence of jumps which are executed at slow speed. Basic steps were executed in different directions 4-8 repetitions consistently: the intermediate march wasn't executed.

In the power block exercises were executed 2 series of 10-16 repetitions in each series. The exercises are executed on average speed. At the end of each series is added fixing of position during 10-15 s.

Selection of aerobic block exercises (the third module) was characterized by a higher coordination complexity. It was trained full-fledged combinations of basic steps with a fitball motion by linear progression method (one step trains, then the following step and then they are connected to each other. Further the third step trains - connected to each other. $1+2+3$ step and so forth). Combinations trains from the right and from the left leg through an intermediate march. It was used motions with high- shock load (Hi): both legs get off a floor (that is the presence of flight phase: jumps and run with the maximum amplitude were used). Hands executed motions from a fitball up.

In the power block exercises executed 3 series of 10-16 repetitions in each series. Exercises were executed consistently one by one. Time for the change of preparatory position - is pauses of active rest.

In the fourth module (the aerobic block) was train a combination from the right and left leg by the linear progression method: the intermediate march has used the minimum. It was used motions with highly shock load (Hi). The rate of music in the aerobic block is 140-142 bpm.

In the power block of exercises were executed 3 series 16-8-4 repetitions in each series at different speed (16 repetitions of exercise were executed in each time signature; 8 repetitions -2 times signature of tension, 2 times signature of rest; 4 repetitions -3 times signature of 
tension, 1 time signature of rest). At the end of each series was fixing of position during 10-15 s.

We didn't use motions which are forbidden in improving aerobics and which provide the "wrong" load of the locomotor system and organism. Selection of tests was carried out considering the program of physical training for students of higher educational institutions [29, 30].

During the research all participants have executed the following tests $[31,32]$ :

- The dexterity development level was estimated by results of 4x9 m shuttle run, sec; high-speed abilities were estimated by results of $30 \mathrm{~m}$ run from the high start, s;

- high-speed and power abilities were estimated by results of a long jump from the spot, $\mathrm{cm}$; the level of static force development was estimated by dynamometer test of the right and left hands, $\mathrm{kg}$;

- dynamic force - by the number of push-ups in lying positions, the number of times;

- coordination abilities - by the time of keeping balance in Romberg's test, s;

- level of flexibility development - a body bends, standing on a gymnastic bench, cm;

- was estimated force of back's and press muscles, times.

Also were defined:

- level of the general physical working capacity $\left(\mathrm{aPWC}_{170}, \mathrm{kgm} \cdot \mathrm{min}^{-1}\right)$ - an integrated indicator of a physical and functional condition of an organism;

- index of physical working capacity (IC, c.u.) - the load complex for estimation of heart reaction to physical activity;

- heart index $\left(\mathrm{HI}, 1 \cdot \mathrm{min}^{-1} \cdot \mathrm{m}^{-2}\right)$ - an indicator of heart function which represents the relation minute volume of heart to total body area;

- Robinson index (IR, c.u.) - estimates a systolic work of heart;

- hypoxia index (IH, c.u.) - characterizes the degree of organism resistance to oxygen deficiency;
- Skibinsky index (IS, c.u.) - characterizes potential opportunities of external breathing system, its resistance to hypoxia, level of coherence functioning with the blood circulatory system;

- level of a functional state of cardiovascular (LFScs, points) and respiratory (LFSrs, points) systems of an organism - integrated indicators of the general functional condition of an organism;

- level of physical health (LPH, points) - an integrated indicator of physical health; body type - an indicator of a correlation between fat and muscular components.

Statistical analysis. All obtained data were processed by means of Microsoft Excel with the calculation of the following indicators: arithmetic mean $(\overline{\mathrm{X}})$; an error of the mean $(\mathrm{S}) ; \mathrm{t}$ - the criterion of the significance of normal distribution. The standard units of measure of the International System of Units SI (SI) were applied in research.

\section{Results}

It was carried out primary comparative analysis of indicators which characterize the level of physical and functional fitness in females of both groups. It was determined the relative uniformity of control and the experimental group at the beginning of the forming experiment (tab. 1).

The females of control and experimental groups had the low value of $30 \mathrm{~m}$ run test; below the average value of indicators: $\mathrm{PWC}_{170}$, Rufie index, $4 \mathrm{x} 9 \mathrm{~m}$ shuttle run, body bends; the average level of Romberg's test.

The females of both groups had a low level of static force value; below an average - in indicators of explosive strength and force of back muscles. All females had the average level of dynamic force and force of press muscles.

Indicators of the blood circulatory system corresponded to the physiologic age norm (tab. 2). The value of Robinson index was registered at the average level. The analysis of initial values of indicators of external breathing system demonstrated the following (tab. 2): at the beginning of

Table 1. Indicators of physical fitness in females of experimental (EG) and control (CG) groups before the forming experiment

\begin{tabular}{lll}
\hline Indicators & EG & CG \\
\hline PWC $_{170^{\prime}}$ kgm $\cdot$ min $^{-1}$ & $546,23 \pm 13,08$ & $540,22 \pm 13,68$ \\
Working capacity index, c.u. & $8,97 \pm 0,53$ & $9,86 \pm 0,33$ \\
Right hand dynamometry, kg & $18,05 \pm 0,89$ & $19,02 \pm 0,73$ \\
Left hand dynamometry, kg & $16,28 \pm 1,05$ & $17,09 \pm 0,97$ \\
Standing high jump, cm & $32,32 \pm 0,8$ & $34,13 \pm 0,72$ \\
Standing long jump, cm & $163,13 \pm 3,51$ & $165,47 \pm 2,51$ \\
Push-ups, times & $19,5 \pm 1,7$ & $20,35 \pm 1,24$ \\
$4 \times 9$ m shuttle run, s & $11,76 \pm 0,2$ & $12,02 \pm 0,17$ \\
30 m run, s & $6,14 \pm 0,07$ & $6,10 \pm 0,07$ \\
Romberg's test, s & $23,34 \pm 4,65$ & $24,05 \pm 1,83$ \\
Bends, cm & $15,18 \pm 1,26$ & $17,32 \pm 0,76$ \\
Abdominal strength, times & $38,39 \pm 1,38$ & $39,51 \pm 1,02$ \\
Back muscular strength, times & $24,15 \pm 1,54$ & $24,89 \pm 1,03$ \\
\hline
\end{tabular}

Note: the significant difference is absent. 
the research females of both groups had indicators value below the physiologic norm; the value of hypoxia index corresponded the average level.

At the beginning of the research, the main part of females of both groups had the average level of a functional condition of the cardiovascular system. Also, female students had the level below an average of functional condition of external breathing system and physical health level.

There weren't female students with high and above an average level of physical health in both groups at the beginning of the forming experiment. At the beginning of the forming experiment, all females had a very good type of body type. There weren't female students with the low type of a body type in general.

The uniformity of the obtained data was a basis for objective assessment of the efficiency of our developed technique. The analysis of the efficiency of applied the fitball aerobics means was carried out on the basis of studied features of indicators' dynamics of physical and functional fitness. Results of the comparative analysis at the end of a research were especially convincing. It was determined significantly higher gain rates of practically all indicators in the experimental group in comparison with control group (fig. 1). Rates of a gain level of physical working capacity in the experimental group were one third higher than in control group of females. Rates of a gain level of flexibility were on a quarter higher. Rates of a gain level of coordination abilities, the force of muscles of abdominal strength and back muscles, were 1,2-1,5 times higher.

It was determined significantly more favorable values of relative changes of indicators of functional fitness in females of the experimental group (fig. 2). The

Table 2. Indicators of functional fitness at girls of experimental (EG) and control (KG) of groups to the forming experiment.

\begin{tabular}{lll}
\hline Indicators & EG & CG \\
\hline Heart index $\mid \cdot \mathrm{min}^{-1} \cdot \mathrm{m}^{-2}$ & $2,84 \pm 0,07$ & $3,01 \pm 0,06$ \\
Robinson index, c.u. & $86,71 \pm 2,43$ & $87,48 \pm 1,46$ \\
Hypoxia index, c.u. & $0,37 \pm 0,03$ & $0,39 \pm 0,02$ \\
Skibinsky index, c.u. & $805,56 \pm 70,2$ & $882,84 \pm 57,86$ \\
LFScs, points & $67,72 \pm 1,43$ & $65,16 \pm 1,4$ \\
LFSrs, points & $44,72 \pm 3,3$ & $45,42 \pm 3,47$ \\
LPH, points & $39,6 \pm 2,45$ & $38,65 \pm 1,63$ \\
Body type, points & $15,37 \pm 0,48$ & $15,72 \pm 0,4$ \\
\hline
\end{tabular}

Note: the significant difference is absent.

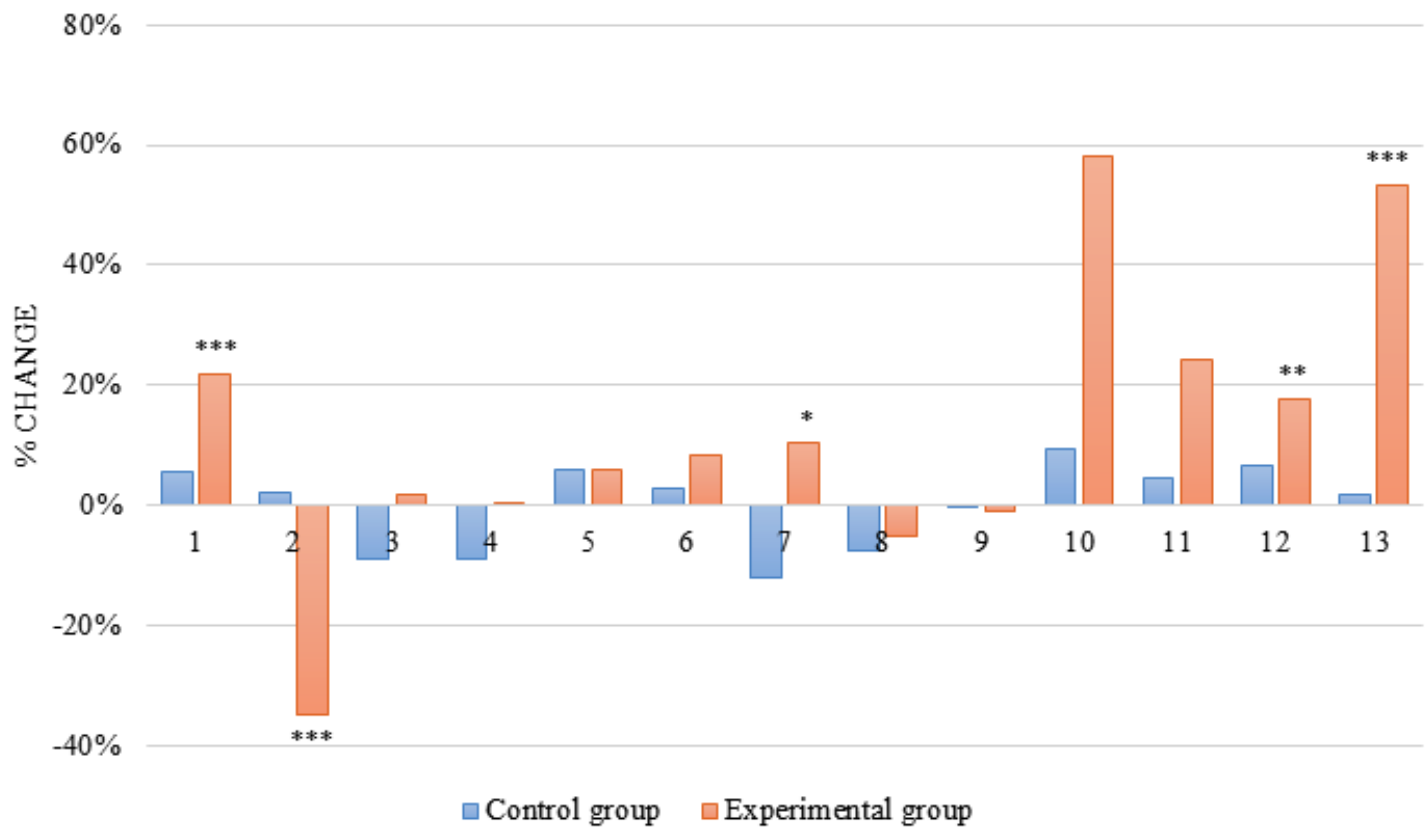

Fig. 1. The gain of physical fitness indicators in females at the end of the research, \% Note: $1-$ PWC $_{170} ; 2-$ working capacity index; 3 - right hand dynamometry; 4 - left hand dynamometry; 5 - standing high jump; 6 - standing long jump; 7 - push-ups; 8 - 4x9 m shuttle run; 9 - 30 m run; 10 - Romberg's test; 11 - bends; 12 - abdominal strength; 13 - back muscular strength; * $\mathrm{P}<0,05, * * \mathrm{P}<0,01, * * * \mathrm{P}<0,001$ in comparison with indicators of females from $\mathrm{CG}$ at the end of the research. 
received results demonstrated that representatives of the experimental group had higher rates of Robinson index decrease and heart index. It was also determined the higher rates of increase in hypoxia indexes and Skibinsky index. The results were higher rates of improvement of a functional condition of the blood circulatory systems, external breathing, level of physical health.

It is rather indicative all these changes are demonstrated in the analysis of the intragroup distribution of females (fig. 3). It was increased the number of females of EG with the average levels of physical working capacity and flexibility (in 1,5 times). It was increased the number of females with high levels of explosive and dynamic strength (in 1,2-1,5 times). It was increased the number of females with the high level of coordination abilities (by 1,2 times). It was increased the percent of females with the level above an average functional condition of the cardiovascular system and the system of external breath has increased (almost in 1,2 times). It was increased the number of females with the average level of physical

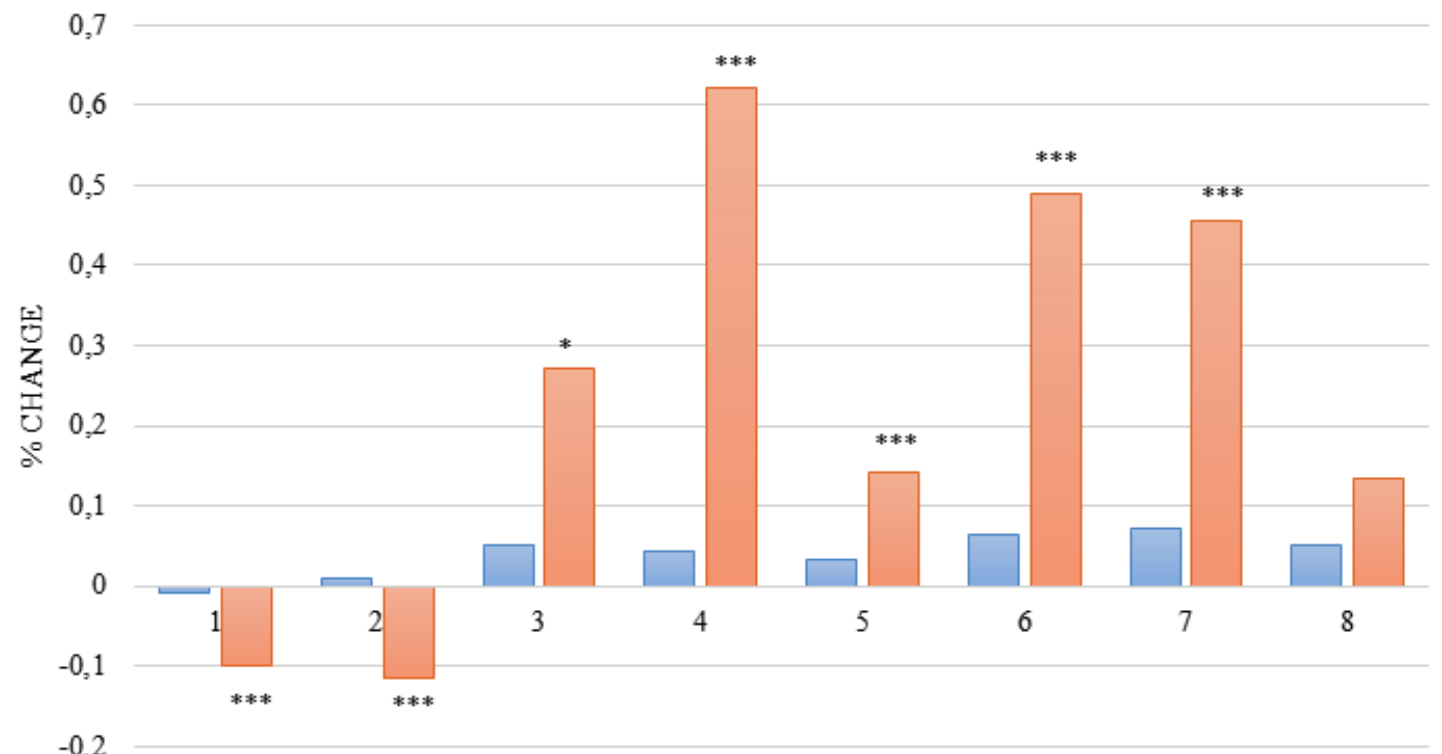

$\square$ Control group $\square$ Experimental group

Fig. 2. The gain of indicators of functional fitness in females at the end of the research, \%: Note: $1-$ heart index; 2 Robinson index; 3 - hypoxia index, c.u.; 4 -Skibinsky index, c.u.; 5 - LFScs; 6 - LFSrs; 7 - LPH; 8 - body type evaluation; $* \mathrm{P}<0,05, * * \mathrm{P}<0,01, * * * \mathrm{P}<0,001001$ in comparison with indicators of females from $\mathrm{CG}$ at the end of the research.

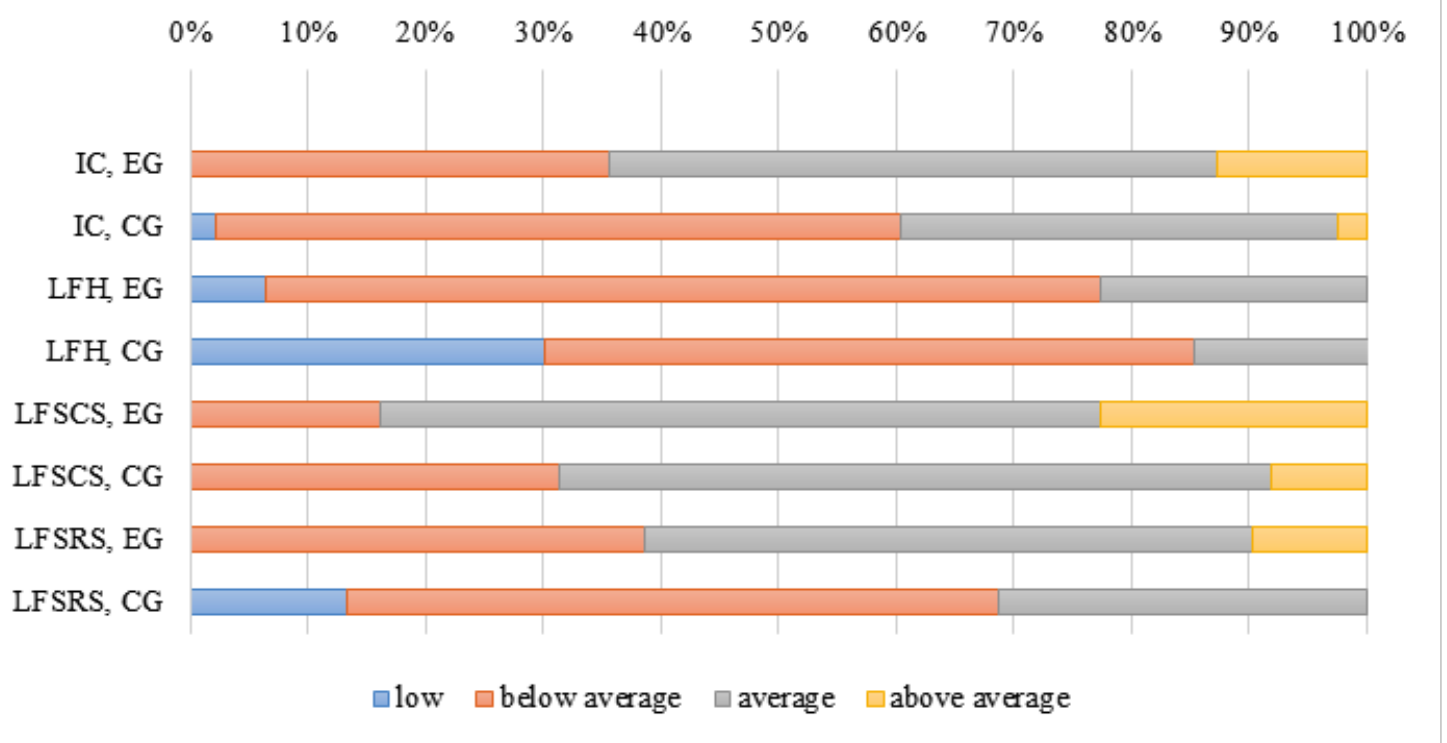

Fig. 3. Intragroup distribution of females of experimental (EG) and control (CG) groups by integrated indicators of physical and functional fitness at the end of the research, \%: Note: IC - index of physical capacity; LFH - the level of physical health; LFScs - the level of functional state of the cardiovascular system; LFSrs - the level of functional state of the respiratory system; CG - control group; EG - experimental group. 


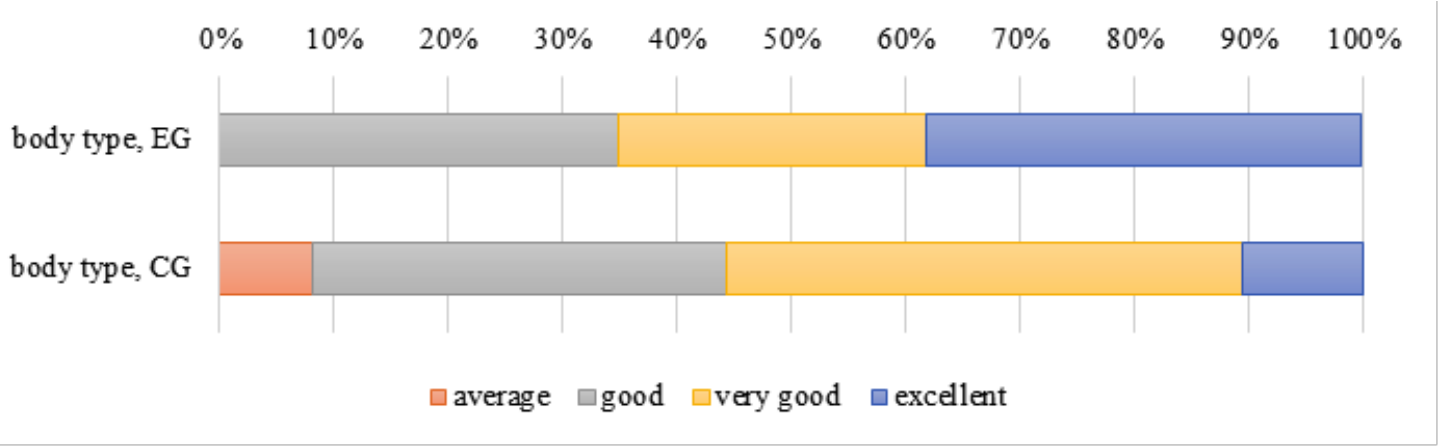

Fig. 4. Intragroup distribution of females of experimental (EG) and control (CG) groups by a body type at the end of a research, \%:

health in 1,2 times. It was increased in a third the number of females with a different type of a body type (fig. 4). All determined positive changes were observed due to the transition of females with the lowest functional classes in higher. Practically all indicators of the females of experimental group corresponded to the higher functional classes than females of the control group.

More detailed analysis of the submitted data allowed to confirm that the most essential were positive changes in females of the experimental group in flexibility, coordination abilities, dynamic force, abdominal strength and back muscles, general physical working capacity, functional condition of the blood circulatory systems, external breathing, level of physical health.

\section{Discussion}

According to the obtained results appeared the need for physical training system optimization of female students of non-sporting specialties. It is connected with the insufficient efficiency of the traditional fitness program.

It coincides with data of other authors [4, 7, 9]. Researchers confirmed low level of physical health of modern female students and stated a discoordination in a functional condition of the blood circulatory systems and external breathing in females of this age. It is also confirmed with our researches which testified the low level of physical and functional fitness of female students.

We developed the experimental program of fitball aerobics training considering specific physiologic features of an organism. The program considers the recommendations of other researchers [19, 22, 23]. The optimum improving effect is observed only in the application of physical exercises which: rationally balanced on orientation, intensity and volume; correspond individual opportunities of the female organisms. For this purpose, we offered technique of training structure with the distribution of physical activities of different orientation in a microcycle. The structure of a microcycle of fitball aerobics training for 2 weeks included 4 training.

In researches of a number of authors $[4,8,20]$ is defined that application of aerobics means promotes optimization only of separate components of a physical condition. Our research expanded data about the influence of a fitball aerobics means on an organism of 18-19-year- olds females. The efficiency of our developed program was estimated by complete, complex monitoring of physical fitness indicators and functional fitness of leading physiologic systems of an organism. It is created a basis of scientific justification of a fitball aerobics means introduction in the physical training system of female students of this age contingent.

Our results allow to claim that introduction of a fitball aerobics means in the system of physical training of 18-19-year-olds female students promotes the significant improvement of all components of physical and functional fitness of their organism. We have realized an integrated approach to the assessment of changes in the current physical and functional state of female students. It was conducted the comprehensive examination of females with simultaneous determination of parameters of physical fitness, the functional fitness of cardiovascular and respiratory systems, physical health and body type. Experimental data were obtained on the basis of the parallel application of modern methodical approaches. It allowed to determine the level of physical fitness, a functional condition of the cardiorespiratory system, physical health and body type. We confirmed results of other researches concerning the importance of the application of different types of physical exercises in the increase in the general physical condition of student's youth.

The added data relatively: physiologic changes in an organism of 18-19 year olds females as a result of systematic physical activities [21]; possibilities of application of modern kinds of aerobics in the system of physical training of students of non-sporting specialties [13]; need of introduction in educational process of such types of physical exercises which are equitable in the greatest measure to interests and motives of students and enjoys popularity [8]. It is expanded scientific data concerning change dynamics of physical condition level of students of 18-19-year-olds in the course of their physical training in a higher educational institution.

\section{Conclusions}

Results of the research allowed to confirm the high efficiency of the developed program of physical training of 18-19-year-olds female students with the application of a fitball aerobics means. Application of the program promoted the significant improvement of physical 
fitness, physical working capacity, physical health, a functional condition of the leading physiologic systems (cardiovascular and respiratory) and to improvement body type.

It is determined that before the end of the forming experiment females of the experimental group of 18 -19-year-olds had significantly $(\mathrm{p}<0,05 ; \mathrm{p}<0,01$; $\mathrm{p}<0,001$ ) higher values of practically all parameters of physical and functional fitness level.

We consider prospects of the subsequent researches studying of opportunities of application of a fitball aerobics means in the course of physical training of senior courses students.

\section{Conflict of interests}

The author declares that there is no conflict of interests

\section{References}

1. Osipov AYu, Kudryavtsev MD, Iermakov SS, Jagiello W. Increase in level of special physical fitness of the athletes specialising in different combat sports (judo, sambo, combat sambo) through of crossFit training. Archives of Budo, 2018;14:1-10.

2. Araki K, Kodani I, Gupta N, Gill DL. Experiences in Sport, Physical Activity, and Physical Education Among Christian, Buddhist, and Hindu Asian Adolescent Girls. Journal of Preventive Medicine and Public Health. 2013;46(1):43-49. doi:10.3961/jpmph.2013.46.S.S43

3. Ilnytska G, Kozina Z, Kaвatsk, O, Kostiukevych $\mathrm{V}$, Goncharenko V, Bazilyuk $\mathrm{T}$, et al. Impact of the combined use of health-improving fitness methods ("Pilates" and «Bodyflex») on the level of functional and psychophysiological capabilities of students. Journal of Physical Education and Sport. 2016;16(1):234-240. doi:10.7752/jpes.2016.01037

4. Kriventsova I, Pashkevych S, Iermakov S, Bartík P, Michal J, Nosko M, et al. Fitness - aerobic training of 15 - 17 years' age girl students, who have significant risk of deviations in backbone functional state. Journal of Human Sport and Exercise. 2017;12(4):1289-97. doi:10.14198/ jhse.2017.124.15

5. Saykina YeG. Fitball aerobics and classification of its exercises. Teoriya i praktika fizicheskoy kul'tury, 2004;7:4346. (in Russian)

6. Donnelly JE, Hillman CH, Castelli D, Etnier JL, Lee S, Tomporowski P, et al. Physical Activity, Fitness, Cognitive Function, and Academic Achievement in Children: A Systematic Review. Medicine and Science in Sports and Exercise. 2016;48(6):1197-1222. doi:10.1249/ mss.0000000000000901

7. Cattuzzo MT, Henrique RD, Re AHN, de Oliveira IS, Melo BM, Moura MD, et al. Motor competence and health related physical fitness in youth: A systematic review. Journal of Science and Medicine in Sport. 2016;19(2):123-129. doi:10.1016/j.jsams.2014.12.004

8. Borras PA, Herrera J, Ponseti FJ. Effects of crossfit lessons in physical education on the aerobic capacity of young students. Journal of Physical Education \& Health, 2017;6 (10):5-11.

9. Yegorova NV., Shesterova LYe. Influence of rhythmic gymnastics' training technique on physical fitness, physical development and functional condition of students I-II courses of technical college. Slobozhans'kij naukovo-sportivnij visnik, 2006;9:10-12. (in Russian)

10.Lavrov NN. Elite fitness: art of a fitball. M. Feniks; 2009. (in Russian)

11.Lyadska OYu. Organizational and methodical grounds of the health-improving fitball training of women of the mature age Kand. Diss. Dnepropetrovsk; 2011. (in Ukrainian)

12.Pappas E, Panou H, Souglis A. The effect of a pilates exercise programme using fitball on people suffering from chronic low-back pain in terms of pain reduction and function improvement. Journal of Physical Education and Sport.
2013; 13(4):606-611. doi:10.7752/jpes.2013.04095

13.Bolotin AE, Bakayev VV, Vazhenin SA. Educational technology of using the system of Pilates for the prevention of spine disorders of female students. Journal of Physical Education and Sport, 2015;15(4):724-729. doi:10.7752/ jpes.2015.04110

14.Carter JM, Beam WC, McMahan SG, Barr ML, Brown LE. The effects of stability ball training on spinal stability in sedentary individuals. The Journal of Strength \& Conditioning Research. 2006;20(2):429-35.

15.Kędra A, Kolwicz-Gańko A, Kędra P, Bochenek A, Czaprowski D. Back pain in physically inactive students compared to physical education students with a high and average level of physical activity studying in Poland. BMC Musculoskeletal Disorders. 2017;18:501. doi:10.1186/ s12891-017-1858-9

16.Stanton R, Reaburn PR, Humphries B. The effect of shortterm swiss ball training on core stability and running economy. Journal of Strength and Conditioning Research. 2004;18(3):522-528.

17.Bogdanovskaya NV, Golubenko AV. Differences in the System of Nitrogen Synthesis and Content of Metabolites in Antioxidant Systems of Sportsmen of Different Sex. American Journal of Biomedical and Life Sciences. Special Issue: Mechanisms of Protection Against Oxidative Stress, 2014;2(6-1):19-24. doi:10.11648/j. ajbls.s.2014020601.14

18.Gibbs JC, Williams NI, Scheid JL, Toombs RJ, De Souza MJ. The association of a high drive for thinness with energy deficiency and severe menstrual disturbances: confirmation in a large population of exercising women. International Journal of Sport Nutrition and Exercise Metabolism. 2011;21:280-90.

19. Shakhlina LG. Medico-biological bases of management of sports training process of women. Dokt. Diss. Kyiv; 1995. (in Russian)

20.Abdulnour J, Razmjou S, Doucet É, Boulay P, Brochu M, Rabasa-Lhoret R, et al. Influence of cardiorespiratory fitness and physical activity levels on cardiometabolic risk factors during menopause transition: Monet study. Preventive Medicine Reports. 2016;4:277-282. doi:10.1016/j. pmedr.2016.06.024

21.Kulinna PH, Martin JJ, Lai Q, Kliber A, Reed B. Student physical activity patterns: Grade, gender, and activity influences. Journal of Teaching in Physical Education, 2003;22(3):298-310.

22.Atamanyuk SI. Peculiarities of development of special endurance and rate-force qualities of high-skilled sportswomen specialized in the sporting team fitness. Kand. Diss. Kyiv; 2006. (in Ukrainian)

23.Falkova N.I. Callisthenic of the students of economical specialties in view of their morphofunctional features. Kand. Diss. Rivne; 2002. (in Ukrainian)

24.Jagiełło M, Iermakov SS, Nowiński M. Differentiation of the somatic composition of students physical education 
specialising in various sports. Arch Budo Sci Martial Art Extreme Sport, 2017;13:63-70.

25.Martin JT, Tubera JG, Monta VD, Naguiat ES, Yambao MJC, Tullao M, et al. Motivation and physical activity participation of Filipino college students. Asia Life Sciences. 2016;25(1):245-254.

26.Donath L, Roth R, Hohn Y, Zahner L, Faude O. The effects of Zumba training on cardiovascular and neuromuscular function in female college students. European Journal of Sport Science, 2014;14(6):569-577. doi:10.1080/17461391 .2013 .866168

27.Ahn JA, Kim JH, Bendik AL, Shin JY. Effects of stabilization exercises with a Swiss ball on neck-shoulder pain and mobility of adults with prolonged exposure to VDTs. Journal of Physical Therapy Science. 2015; 27(4):981-984. doi:10.1589/jpts.27.981
28.Curi VS, Vilaça J, Haas AN, Fernandes HM. Effects of 16-weeks of Pilates on health perception and sleep quality among elderly women. Archives of Gerontology and Geriatrics. 2018;74:118-122. doi:10.1016/j. archger.2017.10.012

29.Dusenko DI. Bases of physical training of students. Kharkiv: KhAI; 2005. (in Ukrainian)

30.Kurochenko IO. The state requirements to training programs on physical training in an education system. Kyiv; 2004. (in Ukrainian)

31.Malikov MV, Bogdanovs'ka NV, Svat'ev AV. Functional diagnostics in physical education and sports. Zaporizhzhya: ZNU; 2006. (in Ukrainian)

32.Malikov MV. Theoretical and applied aspects of adaptation. Zaporizhzhya: ZNU; 2001. (in Russian)

\section{Information about the authors:}

Symonik A. V.; (Corresponding author); http://orcid.org/0000-0001-8574-8744; 020190@ukr.net; Department of Physical Culture and Sports, Zaporizhzhya National University; Zhukovsky str. 66, Zaporizhzhya, 69000, Ukraine.

Chernenko O. Ye.; http://orcid.org/0000-0003-0578-9859; Department of Physical Culture and Sports, Zaporizhzhya National University; Zhukovsky str. 66, Zaporizhzhya, 69000, Ukraine.

Chernenko A. Ye.; http://orcid.org/0000-0001-8689-0873; Department of Physical Culture, Olympic and Non-Olympic Sports, Zaporizhzhya National Technical University; Zhukovsky str. 64, Zaporizhzhya, 69000, Ukraine.

Serdyuk D. G.; http://orcid.org/0000-0002-7120-3118; Department of Physical Culture and Sports, Zaporizhzhya National University; Zhukovsky str. 66, Zaporizhzhya, 69000, Ukraine.

Kokarev B. V.; http://orcid.org/0000-0002-2335-6611; Department of Physical Culture and Sports, Zaporizhzhya National University; Zhukovsky str. 66, Zaporizhzhya, 69600, Ukraine.

Bulakh S. M.; http://orcid.org/0000-0001-7067-4172; Department of Physical Culture and Sports, Zaporizhzhya National University; Zhukovsky str. 66, Zaporizhzhya, 69000, Ukraine.

Hurieieva A. M.; http://orcid.org/0000-0003-3214-4829; Department of Physical Rehabilitation, Sports Medicine, Physical Education and Health, Zaporizhzhya State Medical University; Mayakovsky avenue, 26, Zaporizhzhya, 69035, Ukraine.

Cite this article as: Symonik AV, Chernenko OYe, Chernenko AYe, Serdyuk DG, Kokarev BV, Bulakh SM, Hurieieva AM. Application of fitball aerobics means in the system of physical education of female students of non-sporting specialties. Physical education of students, 2018;22(3):159-166. doi:10.15561/20755279.2018.0308

The electronic version of this article is the complete one and can be found online at: http://www.sportedu.org.ua/index.php/PES/issue/archive

This is an Open Access article distributed under the terms of the Creative Commons Attribution License, which permits unrestricted use, distribution, and reproduction in any medium, provided the original work is properly cited (http://creativecommons.org/licenses/by/4.0/deed.en).

Received: 05.03.2018

Accepted: 01.04.2018; Published: 27.06.2018 